\title{
JUVENTUDE, PROJETOS DE VIDA E ENSINO MÉDIO
}

\author{
GERALDO LEÃO* \\ JUAREZ TARCÍSIO DAYRELL* \\ JULIANA BATISTA DOS REIS ${ }^{* * *}$
}

\begin{abstract}
RESUMO: O artigo apresenta parte dos resultados de pesquisa desenvolvida com jovens estudantes do ensino médio do estado do Pará. Por meio da metodologia de Grupos de Discussão, a pesquisa abordou a realidade do ensino médio na ótica dos jovens, analisando a relação que eles estabeleciam entre os seus projetos de vida e as contribuições da escola para a sua realização. A investigação revelou grande diversidade de projetos juvenis, evidenciando estratégias elaboradas a partir do contexto social, das idades da vida e de uma determinada postura diante do futuro, expressão de um cenário sociocultural marcado pelas incertezas. Os jovens revelaram que a escola é alvo de muitas expectativas, mas apontaram os seus limites em corresponder às suas demandas.
\end{abstract}

Palavras-chave: Juventude. Projetos de vida. Ensino médio.

\section{YOUTH, LIFE PROJECTS AND HIGH SCHOOL}

ABSTRACT: This paper presents some results of research conducted with young high school students in the state of Pará (Brazil). By using the methodology of focus groups, this study discusses school reality from the perspective of youth. It analyzes the relationship they established between their life projects and how school contributes to achieve them. The investigation revealed a great diversity of youth projects. It highlighted both the strategies developed according to social contexts and age and a given attitude towards the future, which is an expression of a socio-cultural landscape marked by uncertainties. These youngsters place many expectations in school, but they show how limited it is to meet their demands.

Key words: Youth. Life projects. High school.

\footnotetext{
* $\quad$ Doutor em Educação e professor adjunto da Faculdade de Educação e do Programa de Pós Graduação em Educação da Universidade Federal de Minas Gerais (UFMG). E-mail: gleao2001@yahoo.com.br

* Doutor em Educação e professor associado da Faculdade de Educação e do Programa de Pós-Graduação da UfMG. E-mail: juareztd@uol.com.br

*** Doutoranda em Educação pelo Programa de Pós-Graduação em Educação da Ufmg e pesquisadora do Observatório da Juventude da mesma Universidade. E-mail: jubtr@yahoo.com.br
} 


\section{JEUNESSE, PROJETS DE VIE ET LYCÉE}

RÉSUMÉ: Cet article présente une partie des résultats d'une recherche développée auprès de lycéens de l'état du Pará (Brésil). Par le biais d'une méthodologie de groupes de discussion, la recherche a ciblé la réalité du lycée sous l'optique des jeunes en analysant les rapports qu'ils établissaient entre leurs projets de vie et la manière dont l'école contribue à leur concrétisation. Cette étude révèle une grande diversité de projets chez ces jeunes. Elle dévoile en outre les stratégies élaborées en fonction du contexte social, des tranches d'âge ainsi qu'un certain positionnement face à l'avenir qui reflète une scène socioculturelle marquée par les incertitudes. Ces jeunes attendent beaucoup de l'école, mais ils indiquent aussi ses limites pour répondre à leurs besoins.

Mots-clés: Jeunesse. Projets de vie. Lycée.

\section{Introdução}

$\mathrm{P}$

ara grande parte dos professores, mas também dos pesquisadores, o jovem que frequenta o ensino médio é compreendido apenas na sua dimensão de aluno. Dessa forma, o ser aluno aparece como um dado natural e não como uma construção social e histórica. Independentemente do sexo, da idade, da origem social ou das experiências sociais vividas, é a sua condição de aluno, quase sempre na sua dimensão cognitiva, que irá informar a compreensão que o professor ou o pesquisador constrói desses atores. $\mathrm{O}$ momento da fase de vida e suas peculiaridades, a origem social, o gênero e a etnia, entre outras dimensões que o constituem como jovem, não são levados em conta e constroem a vida do aluno fora da escola como um tempo vazio de sentido, um não tempo. Nessa compreensão, pouco se apreende sobre os sujeitos reais que frequentam a escola, as múltiplas dimensões da sua experiência social, suas demandas e expectativas.

Levar em conta o jovem existente no aluno implica reconhecer que a vivência da juventude, ${ }^{1}$ desde a adolescência, tende a ser caracterizada por experimentações em todas as dimensões da vida subjetiva e social. O jovem, a princípio, torna-se capaz de refletir e de se ver como um indivíduo que participa da sociedade, recebendo e exercendo influências, fazendo deste o momento por excelência do exercício de sua inserção social. Esse período pode ser crucial para que ele se desenvolva plenamente como adulto e cidadão, sendo necessários tempos, espaços e relações de qualidade que possibilitem experimentar e desenvolver suas potencialidades.

Nesse processo, permeado de descobertas, emoções, ambivalências e conflitos, o jovem se defronta com perguntas como: "Quem sou eu?", "Para onde vou?", "Qual rumo devo dar à minha vida?". São questões cruciais que remetem ao projeto de vida, uma dimensão decisiva no seu processo de amadurecimento. Contudo, para sua elaboração, o jovem, principalmente aquele que frequenta o ensino médio, 
demanda espaços e tempos de reflexão sobre seus desejos, suas habilidades, mas também informações sobre o contexto social onde se insere, a realidade da universidade e do mundo do trabalho, entre outros, de maneira que possa ter elementos para construir um rumo para sua vida.

Como a escola se coloca diante dessa realidade? Será que a instituição escolar, principalmente aquela do ensino médio, seus professores e os gestores buscam conhecer e refletir sobre a realidade dos alunos na sua dimensão de jovens? Será que dialogam com os projetos de vida que elaboram e as demandas e expectativas que colocam em relação à escola? O desafio está posto.

Este texto se propõe a contribuir para esta reflexão, problematizando os projetos de vida de jovens alunos do ensino médio e suas relações com a experiência escolar. Nesse sentido, algumas questões se apresentam: O que os jovens pesquisados pensam sobre o futuro e como elaboram seus projetos de vida? Quais são as suas expectativas e demandas em relação à escola? Suas vivências escolares se relacionam com seus projetos de vida?

\section{Orientações metodológicas}

O artigo apresenta parte dos resultados de pesquisa "Diálogos com o Ensino Médio" ${ }^{2}$ desenvolvida com jovens estudantes do ensino médio do estado do Pará em 2009. ${ }^{3}$ Nela, buscou-se investigar a realidade do ensino médio e seus desafios, na tentativa de superar a lacuna existente na compreensão do aluno dessa modalidade de ensino como jovem. Elegeu-se, a partir dessas orientações, a juventude como uma das categorias centrais de análise e a discussão sobre os projetos de vida como uma das variáveis significativas para a problematização do sentido do ensino médio para os seus estudantes. Nesse sentido, a opção por privilegiar os jovens como sujeitos da investigação é também um pressuposto de pesquisa, ou seja, considerar os jovens alunos como interlocutores válidos e privilegiados para a compreensão do ensino médio.

A escolha dessa perspectiva implicou uma mudança no eixo da análise, passando das instituições educativas para os sujeitos jovens. Ao centrar a investigação em torno dos projetos de vida dos jovens estudantes do ensino médio e da realidade escolar que vivenciavam, buscou-se apreender a relação que estabelecem entre o processo educativo e seus projetos de vida.

Inicialmente, foi elaborado um estudo sobre as características das cidades, das escolas e sobre o perfil dos jovens estudantes do ensino médio no Pará, com base em dados secundários do Instituto Brasileiro de Geografia e Estatística (IBGE) e do Instituto Nacional de Estudos e Pesquisas Educacionais (INEP). Se, em um primeiro 
momento, foi necessário avistar um quadro geral dos contextos social, econômico e cultural em que a população jovem do Pará estava inserida, posteriormente foi imprescindível escutar os sujeitos de pesquisa sobre suas vivências e expectativas. Para alcançar a voz dos jovens, desenvolvemos doze Grupos de Diálogos (GD) com 245 estudantes do ensino médio de três cidades do estado: Moju, Santarém e a capital Belém.

A metodologia dos GD parte do pressuposto de que os sujeitos, colocados em situação de interação e diálogo, estimulados a refletirem sobre um tema proposto, não apenas manifestam suas opiniões, mas partilham, aprofundam e modificam suas percepções, representações e pontos de vista. Com a intenção de motivar a discussão dos GD sobre projetos de vida dos jovens, optamos por apresentar um vídeo produzido e orientado pela equipe de pesquisa. ${ }^{4}$ Nos doze grupos realizados, cada um deles com a duração de quatro horas, os jovens foram convidados a falar sobre seus projetos de vida e as contribuições e não contribuições do ensino médio que eles frequentavam para a sua realização.

\section{Jovens sujeitos de pesquisa}

Para traçar um perfil dos sujeitos de pesquisa, utilizamos os dados colhidos em um questionário que foi respondido individualmente pelos jovens, antes do início das atividades de cada grupo, o que possibilitou delinear um contorno geral e caracterizações desse grupo. No universo de 245 respondentes, 126 jovens eram de Belém, 88 de Santarém e 31 da cidade de Moju.

Levando-se em conta a faixa etária dos participantes, todos eles matriculados no terceiro ano do ensino médio, 95 respondentes (39\%) tinham entre 16 e 18 anos, 85 (35\%) situavam-se entre 19 e 21 anos e 51 (21\%) tinham acima dos 22 anos de idade, sendo que 14 (5\%) não responderam. Isso indica uma defasagem idade/série acima de $60 \%$ dos jovens. Sobre o estado civil, a grande maioria era de solteiros $(90 \%)$, como era de se esperar, sendo uma pequena minoria de casados/"vivendo juntos" (7\%). Entretanto, quando perguntados se tinham filhos, $16 \%$ responderam positivamente, indicando que havia uma parcela de pais e mães solteiros.

Outro dado significativo refere-se ao trabalho: dos jovens pesquisados, 38,4\% (94) estavam trabalhando no período da pesquisa, ao passo que $61,6 \%$ (151) estavam desempregados ou nunca trabalharam. Assim, para uma parcela significativa deles, o trabalho era uma dimensão importante da condição juvenil, permitindo garantir o mínimo de recursos para o lazer, o namoro ou o consumo. Para muitos, a iniciação ao trabalho ocorreu ainda na adolescência, por meio dos mais variados "biscates", caracterizando uma situação de instabilidade que tende a persistir ao 
longo da juventude. Mas isso não significava, necessariamente, o abandono da escola, apesar de influenciar no seu percurso escolar. Os dados mostram que, até os 18 anos, praticamente $20 \%$ dos jovens conciliavam escola e trabalho, proporção que vai diminuindo com o avanço da idade. Em torno de $35 \%$ dos jovens contribuíam de alguma forma para o sustento da família.

Sobre a trajetória escolar, podemos constatar que boa parte dos jovens apresentava um percurso irregular. Levando em conta a faixa etária, podemos observar a existência de $56 \%$ dos jovens em uma faixa acima daquela que seria esperada ( 15 a 17 anos), revelando uma defasagem idade/série considerável, como vimos anteriormente. Buscando problematizar tais dados, as informações sobre a reprovação nos mostram que $43,7 \%$ dos jovens já haviam sido reprovados pelo menos uma vez. Isso indica uma experiência escolar marcada por insucessos, o que certamente influenciava no envolvimento do jovem com a própria escola. Esses dados são reforçados pelo número significativo de quem já interrompeu a vida escolar (27,3\%).

Ainda sobre a trajetória escolar dos jovens, outro dado importante refere-se à escolaridade dos pais. Temos que $77,6 \%$ dos pais não chegaram a completar o ensino médio, índice que cai para $64,1 \%$ no caso das mães. Assim, a grande maioria dos jovens pesquisados apresentava uma escolaridade maior do que a de seus pais, reflexo da expansão do ensino médio no Pará e no Brasil. Ou seja, encontram-se inseridos em uma família com pouca tradição escolar, o que interfere nas suas trajetórias.

Os dados apresentados através desta amostra da pesquisa nos oferecem representações sobre os concluintes do ensino médio no estado do Pará. O instrumento da coleta de dados por questionários complementa um olhar sobre a condição juvenil e se fundamenta na perspectiva de compreender os atores centrais na escola de ensino médio, fornecendo elementos para compreender os projetos de vida dos jovens pesquisados.

\section{Juventude e projetos de vida}

Inicialmente, torna-se necessário explicitar o que entendemos por projeto de vida. Partimos da ideia, inspirados em Schutz (1979), de que o projeto de vida seria uma ação do indivíduo de escolher um, entre os futuros possíveis, transformando os desejos e as fantasias que lhe dão substância em objetivos passíveis de ser perseguidos, representando, assim, uma orientação, um rumo de vida. Nesse sentido, o projeto não deve ser entendido como resultado de um cálculo matemático, estrategicamente elaborado, ou de um processo linear, como está presente no senso comum.

A ideia de projeto de vida remete a um plano de ação que um individuo se propõe a realizar em relação a alguma esfera de sua vida (profissional, escolar, afetivo 
etc.) em um arco temporal mais ou menos largo. Tais elaborações dependem sempre de um campo de possibilidades dado pelo contexto socioeconômico e cultural no qual cada jovem se encontra inserido e que circunscreve suas experiências.

Nesse sentido, o projeto possui uma dinâmica própria, transformando-se na medida do amadurecimento dos próprios jovens e/ou mudanças no seu campo de possibilidades. Eles nascem e ganham consistência em relação às situações presentes, mas implicando, de alguma forma, uma relação com o passado e o futuro. Nesta formulação, falar em projeto é referir-se a uma determinada relação com o tempo, em especial o futuro, e especificamente às formas como a juventude lida com esta dimensão da realidade.

\section{O tempo e os projetos de vida na modernidade}

Partimos da ideia de que o modo de conceber e de viver o tempo não é um dado natural, muito menos metafisico, mas uma dimensão sociocultural que vem se modificando com o suceder das gerações, de acordo com o contexto histórico e cultural de cada grupo social. Nesse sentido, a relação entre passado, presente e futuro também vem se transformando ao longo da história humana (Leccardi, 1991). A noção de futuro como uma dimensão autônoma, por exemplo, é muito recente na história humana, aparecendo relacionada à noção de progresso, ideias hegemônicas com o advento do capitalismo. É nesse contexto que podemos situar a noção moderna de projeto de vida.

Segundo Leccardi (2005), a partir dos seculos Xvir e XviII afirma-se uma concepção linear do tempo na razão cultural europeia, concorrendo com a noção de tempo cíclico, hegemônico até então. A partir da nova organização do trabalho na sociedade industrial, ganha terreno uma concepção de tempo no qual o passado, presente e futuro inscrevem-se em um fluir incontido, esvaziado de qualquer outro sentido senão o de ser um processo estruturado por um antes e um depois. Passa a se afirmar uma concepção de mundo diferente, secularizada, na qual o progresso (mundano) toma o lugar da perfeição (espiritual). Nesta perspectiva, afirma a autora, "o futuro é subtraído da dupla influência divina e natural, e submetido ao dominio humano. Abre-se, assim, tanto ao novo como ao incerto, a um futuro aberto" (Leccardi, 2005, p. 41).

A noção de futuro aberto passa a exercer uma influência profunda nos esquemas culturais da modernidade, estando de alguma forma presente até hoje. Nesta concepção, o devir aparece ligado, por um duplo fio, às escolhas e às decisões do presente. O futuro, de modo análogo à história, não se repete: é o terreno do novo, do inédito, é um agente do progresso. Nesta visão otimista, o tempo 
aberto e irreversível do futuro avança, sem incertezas, na direção de um indiscutivel melhoramento. Neste contexto, nos fala Leccardi, a perda da instância metassocial na relaçâo com o futuro faz emergir a centralidade da "autonomia do indivíduo: não mais sua posição definida, mas sua capacidade de projetar-se individualmente torna-se a fonte primária da identidade e o princípio organizador da biografia" (idem, ibid., p. 42). Assim, o futuro aparece como um horizonte temporal subjetivamente influenciável, à disposição dos indivíduos como espaço de experimentação, e a projeção do tempo torna-se uma forma de controlar a incerteza do futuro através das próprias forças intelectuais. Construir o futuro significa se aparelhar para enfrentar a descontinuidade, sendo um equivalente moderno das práticas mágicas das sociedades arcaicas. No futuro aberto, afirma a autora, liberdade e incerteza aparecem como as duas faces de uma mesma cabeça.

É este contexto que explica o surgimento de uma determinada ideia de projeto de vida, aliada ao mecanismo do "adiamento das recompensas", fortemente enraizado no senso comum até os dias de hoje. Implica basicamente a determinação em adiar, para um tempo vindouro, a satisfação possível que o tempo presente pode garantir, em vista dos benefícios que esse adiamento torna possivel. Nessa perspectiva, o tempo presente não é apenas a ponte entre o passado e o futuro, mas a dimensão que "prepara" o futuro. É este que dá sentido ao agir no presente, constituindo-se não só como o espaço privilegiado de construção do projeto de vida, como também para a definição de si. Dessa forma, há uma correspondência entre a biografia e o projeto, um estruturando-se em função do outro. A partir dessa lógica, a inserção social dos jovens se consagra como resultado das capacidades individuais de elaborar um determinado projeto de vida e persistir no mesmo, tornando-se uma responsabilidade pessoal que vai explicar (e justificar) o lugar social que passará a ocupar quando adulto. Tal concepção, apesar de não ser mais hegemônica, encontra-se ainda presente no imaginário social contemporâneo, disputando com outros modelos e concepções.

\section{O tempo e os projetos de vida na contemporaneidade}

A partir de meados do século $x x$, a sociedade ocidental passa por um conjunto de mutações sociais profundas que vem afetando diretamente a realidade social e suas instituições. A constituição dos mercados globais, a velocidade das transformações tecnológicas, o pluralismo dos valores e das autoridades, o individualismo institucionalizado e a ampliação dos riscos e das incertezas são algumas das expressões de um novo cenário, que alguns autores, como Melucci (2004), chamam de "sociedade complexa". Esse contexto interfere diretamente na produção social dos jovens e na forma como se relacionam com o tempo. 
Nesse cenário, os indivíduos se encontram envolvidos numa pluralidade de pertencimentos (posições sociais, redes associativas, grupos de referência etc.), de tal forma que participam, real ou imaginariamente, de uma multiplicidade de mundos: "somos animais migrantes nos labirintos das metrópoles, viajantes do planeta, nômades do presente" (Melucci, 2004, p. 39). Cada um é chamado a escolher, a decidir continuamente, fazendo com que a incerteza faça parte da ação: diante da ampliação das possibilidades, o que fazer? Quais possibilidades escolher? O imperativo da incerteza impõe a necessidade da escolha. É o que ele chama de "paradoxo da escolha": de um lado, a ampliação do espaço de autonomia individual que se expressa na escolha. Mas, de outro, a impossibilidade de não escolher. Isso não significa afirmar que "todos escolhem tudo, sempre", pois seria negar a existência dos diferentes tipos de fundamentalismos ou mesmo das desigualdades sociais. O que Melucci evidencia é a centralidade da escolha no cotidiano, no qual as tarefas mais banais tornam-se exercícios para solução de problemas, exigem a aquisição de informações, a leitura de instruções para uso, e, no fim, requerem escolhas.

A esta ampliação das incertezas em todos os níveis da vida social se soma uma ampliação do sentimento e da ideia do risco. A crise ambiental, o terrorismo internacional, as crises econômicas, o surgimento de novas epidemias globais, as novas formas de desigualdade social, entre outras, são expressões de uma realidade que coloca em xeque as dimensões da segurança, certeza ou controle tão típicas da sociedade moderna (Beck, 1998). Todos estes riscos globais, humanamente produzidos, levam a uma reelaboração da ideia de futuro. Se antes dominava o futuro aberto, passível de colonização na direção de uma terra prometida, na contemporaneidade o futuro passa a ser indeterminado e indeterminável, governado pelo risco. Ou seja, o futuro foge do controle, gerando um sentimento difuso de alarme, associado a uma sensação de impotência. Nesse sentido, a contemporaneidade inaugura novas formas de temporalização. O futuro se torna passível de perder o seu sentido como um tempo progressivo, controlável e planificável. Diante de um cenário marcado pelas incertezas e pelos riscos, a busca de sentido é transferida para o presente, num eixo temporal curto que tornaria possível o seu controle.

Segundo Leccardi (1991), a governabilidade fixa-se no presente tecnologicamente veloz e flexível. Para a autora, o presente de hoje não é mais só a ocasião e o lugar, quando e onde se formulam as questões às quais se responde interrogando o passado e o futuro, mas também é a única dimensão do tempo que é vivida sem maiores incômodos e sobre a qual é possível concentrar a atenção. É o que ela chama de presente estendido, um espaço temporal que bordeja o presente, suficientemente breve para não fugir ao domínio humano e social, mas também suficientemente amplo para consentir alguma forma de projeção para além no tempo. Nesse sentido, afirma Leccardi (op. cit.), o presente (ora mais, ora menos estendido) aparece como 
a única dimensão temporal disponível para a definição de escolhas, um verdadeiro horizonte existencial que, em certo sentido, inclui e substitui futuro e passado. $\mathrm{O}$ futuro deixa de ser uma fronteira a ser superada e um fim que orienta o presente, tornando-se um horizonte, descontínuo e dinâmico, numa fragmentação da experiência com o tempo. É neste contexto que podemos situar a formulação dos projetos de vida pelos jovens pesquisados.

\section{Os jovens pesquisados e seus projetos de vida}

Nos diferentes Grupos de Diálogos (GD) realizados, no contexto da metodologia já explicitada anteriormente, os jovens fizeram as mais diferentes elaborações sobre seus projetos de vida. De uma maneira geral, podemos afirmar que centraram suas formulações em torno das expectativas de escolarização articuladas com o mundo do trabalho, indicando uma determinada profissão desejada. Nesse sentido, reforçam a centralidade da escola e do trabalho na constituição de uma determinada condição juvenil.

Uma grande parte dos jovens expressou seus projetos de uma forma mais geral, sem mencionar os meios e as estratégias necessárias para alcançá-los. No geral, expressaram o desejo da finalização do ensino médio e a continuidade dos estudos em um curso superior que lhes possibilitassem ter acesso a uma profissão, em formulações que apareciam mais como um sonho do que uma meta a ser perseguida. Esta dimensão do sonho fica ainda mais evidente na escolha de qual curso seguir, o que, para muitos, ainda é objeto de dúvidas. Em muitos casos, manifestava-se uma falta de reflexão sobre seu desejo e suas potencialidades pessoais, mas também certo desconhecimento acerca das profissões escolhidas. Podemos afirmar que grande parte dos participantes dos GD demonstrou a falta de uma reflexão mais sistemática sobre suas perspectivas de futuro anteriormente aos grupos, ao mesmo tempo em que expressaram muitas dúvidas sobre os cursos desejados, bem como sobre a realidade do mundo do trabalho local. Parecia haver uma postura diante do tempo futuro que, em face da indeterminação e incerteza predominantes, transmutava o projeto em sonhos, como vimos na discussão anterior. Outro desejo expresso por alguns jovens era a constituição de uma família, articulada à conquista de uma estabilidade, desejo este mais presente entre aqueles com idade mais avançada.

Boa parte dos depoimentos também remeteu a uma justificativa para o desejo de tal estabilidade. Ajudar a família (os pais, mas, principalmente às mães) foi algo recorrente nas respostas. Além disso, o desejo da formação de uma família (marido/esposa/filhos) foi algo presente junto à perspectiva de boas condições de sustento da mesma, principalmente entre as mulheres e, especificamente, entre as mais velhas. Nesse sentido, a família se coloca como uma instância significativa para 
a compreensão dos projetos de vida dos jovens, nos quais ocupa um lugar central tanto como motivação para sua formulação quanto no conteúdo expresso. Através dos projetos, os jovens entrevistados revelavam um sentido de obrigação em relação à família, mas existia também a dimensão moral de uma retribuição aos pais pelo que já receberam até então. Nesse sentido, a família - e nela principalmente a mãe - aparecia como uma instância moral estruturada a partir do eixo do "dar, receber, retribuir", segundo uma moral da reciprocidade (Mauss, 1974), diante da qual os jovens sentem-se na obrigação de um dia retribuir pelo que fizeram a eles até então.

Dessa forma, apesar da diversidade existente entre os jovens participantes, principalmente relacionados à questão da idade, do gênero, da raça, do espaço geográfico, os projetos de vida expressos por eles revelam um conjunto de aspectos aparentemente comuns que demandam um esforço de análise.

Podemos categorizar os projetos de vida expressos pelos jovens pesquisados em um continuum, no qual, em um dos extremos, situam-se aqueles que de alguma forma expressam um mínimo de clareza do que querem para si: o desejo de continuidade dos estudos através do ingresso no ensino superior, uma formulação majoritária entre eles. Este fato em si já denota uma novidade desta nova geração de jovens que, diante da expansão do ensino médio e do ensino superior no Brasil, passam a vislumbrar esta perspectiva, o que não ocorria na geração dos seus pais. Estes, no geral, apresentavam uma escolaridade mais baixa do que a dos filhos.

As estratégias formuladas para esta continuidade dos estudos mostraram-se diferenciadas. Para boa parte deles, o desejo de continuidade dos estudos era formulado por meio de uma inserção imediata no ensino superior, logo após a conclusão do ensino médio. Boa parte dos jovens incluídos neste eixo apresentava como perfil o fato de serem mais novos, sem maiores defasagens idade/série; frequentavam o curso diurno e não se encontravam inseridos no mercado de trabalho. Uns poucos já investiam na viabilização deste projeto, como fazer cursinhos pré-vestibulares, por exemplo, visto como um pré-requisito básico, principalmente para aqueles oriundos da escola pública. Mas a grande maioria formulou seu projeto de forma genérica, apontando o desejo de continuidade dos estudos através de um curso, mas sem demonstrar conhecer de fato as especificidades dos diferentes cursos, as possíveis dificuldades que tal escolha acarretaria, nem mesmo os mecanismos existentes no estado do Pará para o acesso à universidade pública. ${ }^{5}$

Para outros jovens, os projetos apontavam o desejo de uma continuidade dos estudos no ensino superior, mas com a estratégia de fazê-lo depois de conseguirem certa estabilidade através de um curso técnico, um emprego mais estável ou mesmo por meio da realização de um concurso público. O perfil destes jovens se diferenciava do grupo anterior, caracterizando-se na sua maioria por serem jovens com idade 
mais avançada, frequentando o turno noturno, com experiências as mais variadas no mercado de trabalho, principalmente em trabalhos temporários ou no setor de serviços, alguns deles já casados e com filhos.

Os depoimentos destes jovens evidenciam uma realidade comum a grande parcela daqueles que se encontram no ensino médio e que, sonhando com o ensino superior, se defrontam com as dificuldades inerentes ao meio social de origem. Muitas vezes, a pobreza os levava a uma inserção precoce no mercado de trabalho, o que os obrigava a conciliar o trabalho e o estudo, fato que interferia na qualidade e no envolvimento com a escola, sendo um entre outros vários motivos a gerar uma trajetória escolar irregular. Além destes fatores, algumas jovens viveram a questão da gravidez precoce, que também interferiu diretamente na trajetória escolar.

Esta realidade fazia com que estes jovens tivessem uma postura mais pragmática diante de seus projetos. Por conta da necessidade imperiosa da sobrevivência, postergavam o sonho da inserção no ensino superior. Como dizia um deles: "a gente quer o que todo mundo quer que é fazer uma faculdade, mas o problema é fazer...". Este jovem revelava assim a consciência das barreiras a serem enfrentadas na concretização dos seus sonhos. Um fato revelador é que a grande maioria desses jovens falava em ingressar em faculdades particulares, fazendo referências explícitas às desigualdades de acesso à universidade, com críticas a uma realidade na qual "uns tem mais oportunidades", ou mesmo às universidades públicas nas quais "só entram quem tem dinheiro". O certo é que a grande maioria destes jovens vivia um dilema: queriam estudar, mas precisavam trabalhar para garantir os próprios estudos. Podemos constatar o esforço deles em elaborar estratégias para lidar tanto com as incertezas, como também com os limites estruturais nos quais se inseriam, o que nos mostra as formas como a desigualdade social se manifesta em suas vidas.

No entanto, havia também aqueles, uma minoria, que afirmavam não querer continuar os estudos para além do ensino médio, pretendendo apenas disputar uma vaga no mercado de trabalho em uma posição melhor. Parece-nos, neste caso, que a escola não conseguiu despertar nestes jovens o desejo e o prazer do conhecimento. Para eles, o horizonte temporal ainda era mais curto: queriam o que já vivenciavam no presente, se resignando com esta realidade, sem vislumbrarem outras possibilidades para si mesmos ou se proporem a superar os desafios além daqueles que surgem no cotidiano. Ou, quando o faziam, apontavam possibilidades bem próximas daquelas que já vivenciavam, como fazer concursos públicos que demandavam pouca escolaridade. Podemos dizer que, a princípio, eram eles os candidatos a se reproduzirem como trabalhadores desqualificados.

Finalmente, ainda neste continuum, encontramos um número significativo de jovens que expressavam dúvidas em relação aos projetos pretendidos, seja na escolha 
do curso a ser seguido, seja naquilo que realmente queriam, em uma postura de incerteza diante do futuro. Como dizia uma das jovens: "eu não sei o que é que vai ser da minha vida".

Não foi possível traçar um perfil comum a estes jovens, já que a incerteza estava presente entre todos os segmentos, indicando ser uma postura comum presente na diversidade de modos de ser jovem daqueles pesquisados. Mas as dúvidas e incertezas foram expressas de forma diferenciada. Para alguns, o futuro aparecia como totalmente indeterminado: "Eu ainda não me identifiquei com nada. Eu não sei ainda o que eu quero fazer", apontando para parcelas da juventude que se fixam no presente, sem maiores investimentos na reflexão sobre o seu futuro. Outros já expressavam dúvidas de uma forma mais geral: "As dúvidas são grandes, fico pensando em fazer o que gosto ou ganhar bem?". Neste caso, a incerteza se referia a por qual caminho optar. Chamava a atenção o fato de se colocar as duas possibilidades como excludentes, como se não fosse possível um projeto onde estivessem conciliados o desejo, as potencialidades subjetivas e o prazer com uma boa remuneração. Para outros, a dúvida situava-se na escolha do curso desejado, evidenciando o desafio enfrentado pelos jovens neste momento do curso da vida, quando se viam diante das múltiplas opções que possuíam pela frente, em uma ampliação do universo de possibilidades vislumbradas em função da expansão do ensino superior no Pará e no Brasil. Um grande desafio que os jovens indicavam para esta escolha era a falta de informação sobre o que o ensino superior oferece na região, as características dos cursos, as exigências e as possibilidades de cada um deles, indicando uma demanda para a escola.

Neste continuum de projetos, as diferentes posturas diante do futuro podem ser entendidas como a busca de estratégias que os sujeitos construíam para lidar com o contexto em que se formavam e no qual se encontravam, ou seja, o seu campo de possibilidades; mas, também, com os recursos materiais e subjetivos a que tinham acesso, com a qualidade da sua trajetória escolar, o acesso ou não às informações sobre o ensino superior e sobre o mundo do trabalho, entre outras variáveis que interferiam diretamente na capacidade de lidar com o futuro, em um contexto social dominado pelas incertezas, como vimos anteriormente.

Nesse sentido, os jovens participantes da pesquisa, no contexto da sua diversidade, parecem evidenciar uma determinada postura diante do futuro, expresso através dos projetos de vida. A conexão íntima entre projeto, trajetória biográfica e identidade - que, como vimos, era dominante na modernidade - parece se diluir, com o futuro deixando de ser a referência para o presente, dimensão temporal que parece dominar na elaboração de projetos de vida, com arcos temporais mais curtos, na forma de um presente estendido. 
Talvez a melhor forma de caracterizar os projetos de vida destes jovens seja através da metáfora do bricoleur. Para Levi Strauss (1989), o bricoleur é aquele que executa um trabalho com as próprias mãos, empregando os materiais disponíveis, adaptando-os para construir passo a passo o equipamento necessário. Sem ter um projeto muito claro no início, ele vai sendo construído ao sabor do momento, lançando mão de peças disponíveis e que não têm nenhum emprego pré-determinado. Os resultados do trabalho construído são, portanto, contingentes, podendo inclusive ser diferentes da intenção inicial. Assim, os projetos de vida tendem a ser elaborados na medida da experimentação de si no contexto de um determinado campo de possibilidades, sem metas rígidas, em um processo de exploração marcado pela provisoriedade. O depoimento de um jovem de Santarém sintetiza bem esta forma de elaboração de projetos por parte desses jovens:

\begin{abstract}
Desde o inicio, quando a gente começa se desenvolvendo como homem, como moça, a dúvida vem batendo e vem mudando conforme a gente vai vivendo. A gente quando é o primeiro filho homem, o sonho da gente, que a gente fica ouvindo o pai da gente falar é: ou vai ser jogador de futebol ou do exército, militar, vai se formar. Então, era esse o meu sonho primeiro o exército. Foi mudando, porque quando entrei em 18 anos, com 19 anos eu mudei de cidade. Então, a gente se apresentando em outra cidade, a prioridade maior é pra aquelas pessoas daquela cidade. Eu fui morar no Amapá. Então, lá encerrou o meu primeiro sonho. Aí eu comecei a frequentar a igreja e o meu sonho daí em diante era ser pastor. Mas aí apareceu uma mulher na minha vida e me tirou do caminho. Mais um sonho que se foi (...). Depois que voltei a estudar aqui, o professor de geografia me fez gostar de geografia (...). Isso me chamou atenção e me levou a ter essa ascendência de me formar pra geografia, de terminar esse $3^{\circ}$ ano, de prestar o vestibular ou fazer alguma coisa mais desenvolvida... esse é o meu outro sonho. A gente conforme vai andando, vai aprendendo e tirando aquela dúvida. A gente planeja uma coisa, mas não tem condição de ser aquilo. (H, 23 anos, GD 5)
\end{abstract}

Os depoimentos destes jovens parecem indicar que a constituição da condição juvenil vem ocorrendo de forma cada vez mais complexa, com o jovem vivendo experiências variadas e, às vezes, contraditórias, expostos que estão a universos sociais diferenciados, a laços fragmentados, a espaços de socialização múltiplos, heterogêneos e concorrentes. Constitui-se como um ator plural, produto de experiências de socialização em contextos sociais múltiplos, expressando os mais diferentes modos de ser jovem (Dayrell, 2007).

Diante de estruturas sociais cada vez mais fluidas, marcadas pela fragmentação do tempo e sob o domínio das incertezas, reforçadas pelo contexto social no qual se encontram inseridos, estes jovens parecem sentir a vida marcada por crescentes inconstâncias, flutuações, descontinuidades, movimentos autênticos de vai e vem. É o que Pais (2003) caracteriza como o princípio da reversibilidade, expressa no constante "vaivém" presente em todas as dimensões da vida desses jovens, inclusive na escolha dos possíveis cursos que se propõem a frequentar. 
Parece-nos que esta reversibilidade contém e expressa os modos como estes jovens lidam com o tempo e seus projetos. Como na metáfora do bricoleur, o que domina é o principio da experimentação, através do qual testam suas potencialidades, improvisam, se defrontam com seus próprios limites, lançando mão das possibilidades que lhes surgem. Acreditamos que o momento da pesquisa possa ser visto como uma experiência que estes jovens vivenciaram e durante a qual refletiram, muitos deles talvez pela primeira vez, sobre seus projetos de vida. Nesse sentido, os GD podem ter significado para muitos o momento de inserir "uma peça" a mais na construção do seu projeto.

Não podemos nos esquecer da dinamicidade que imprimiam nos seus projetos e, tal como o bricoleur, o ponto de chegada destas trajetórias é incerto, sendo resultado da capacidade individual de construir e reconstruir novos rumos, novos sentidos diante das novas experiências. É nesse processo, marcado pela transitoriedade, que vão se delineando as trajetórias para a vida adulta, que tendem a ser cada vez mais individualizadas, sem modelos prévios aos quais possam se mirar, conformando os mais diferentes percursos.

Diante deste contexto de incerteza, cabe a questão: em que medida a escola, o ensino médio, vem contribuindo para que estes jovens elaborem seus projetos? Ela contribui para que eles se conheçam mais, construam uma identidade positiva e conheçam o campo de possibilidades onde se encontram inseridos? Em que medida a escola vem contribuindo para uma inserção social mais qualificada destes jovens como cidadãos? É o que pontuaremos a seguir.

\section{Os jovens, seus projetos e o ensino médio}

A descrição e análise dos projetos formulados pelos jovens pesquisados possibilitam levantar algumas considerações. Uma primeira diz respeito ao contexto social no qual estes vieram se construindo como sujeitos sociais. O depoimento abaixo de um jovem de Belém sintetiza bem este contexto:

\footnotetext{
No meu caso eu só tenho a minha mãe porque o meu pai faleceu quanto eu tinha nove anos. Eu passei muitas dificuldades com a minha mãe devido a estar desempregada. Até certo ponto, porque foi os parentes que ajudavam a gente. A minha mãe não é formada (...). Desde os dez anos eu trabalho com meu tio em oficina. Sempre procurei ajudar a minha mãe. Só que nunca deixei os meus estudos (...). Hoje ela é funcionária pública. Ela fez um concurso e passou. Eu fico vendo as dificuldades que a gente passou... (...). Eu estou pensando em fazer Educação Física, mas na área em que eu estou atualmente, de escritório e tal, tem mais mercado de trabalho atualmente. Então eu estou pensando em mudar, não sei. Até porque, eu penso assim, na área da Educação Física eu não sei se vai ter emprego no futuro (...). Eu penso em me formar para, principalmente, dar uma boa vida para a minha família, para a minha mãe, para pelo menos retribuir o que ela
} 
fez pra minha irmã e por mim. Eu acho que eu sou muito precoce. Desde pequeno que eu venho trabalhando, venho conquistando o meu espaço, dinheiro e tal... Um conselho que eu vou dar a todos vocês: quando tiverem um sonho no futuro, retribuir alguma coisa que fizeram por você, não desiste do sonho de vocês. (H, 18 anos, GD 8)

Este depoimento fala por si, sintetizando várias das questões já abordadas anteriormente, como o desafio cotidiano da sobrevivência e o trabalho precoce, mas também a persistência na frequência à escola e a centralidade da família, especialmente das mães. Diante de um cenário marcado pelas incertezas, a grande maioria elaborava seus projetos na forma de sonhos. É o sonho de uma vida melhor, mais digna, onde pudessem se realizar como jovens e como cidadãos. E neste sonho expressavam o desejo de "ser mais": mais iguais, mais humanos, com uma vida mais digna.

Na forma como elaboravam os seus projetos, pudemos identificar o desejo comum da inserção no ensino superior como uma aposta nas "promessas da modernidade". Independentemente de traduzir os seus sonhos em ações concretas e viabilizá-los, só a expressão dos mesmos já era muito significativa. Para uma grande parcela destes jovens, geralmente os mais novos, sem maiores experiências no mundo do trabalho, a escola se colocava como um espaço privilegiado para a realização dos seus sonhos. Para estes, a exigência seria por um ensino médio que os capacitasse a concorrer de forma mais igualitária nos processos seletivos da universidade pública. Já para outros, mais amadurecidos pelas experiências de vida e trabalho, muitos deles com família já constituída, a expectativa escolar era mais urgente. Esperavam um ensino técnico que os capacitassem a disputar o mercado de trabalho com uma qualificação maior. Essa realidade parece apontar uma demanda dos jovens pela oferta de diferentes modalidades para o ensino médio, de tal forma a contemplar a diversidade de experiências juvenis com suas necessidades próprias.

Podemos perceber um continuum diferenciado de posturas diante do futuro, que se expressava nas mais diferentes formas de elaboração dos projetos de vida. Estes podem ser vistos como a busca de estratégias que os sujeitos constroem para enfrentar essas transformações socioculturais aqui discutidas e, sempre que possível, controlá-las. Mas é sempre um desafio que exige cada vez mais habilidades de manter uma direção ou trajetória a despeito da impossibilidade de prever seu destino final. Se essa é uma realidade comum à juventude, no caso dos jovens pesquisados os desafios eram ainda maiores, uma vez que contavam com menos recursos e margens de escolhas, imersos que estavam em constrangimentos estruturais.

A escuta desses jovens nos permite constatar que a escola tinha uma grande importância nas suas vidas, sendo uma instituição para a qual dirigiam muitas expectativas. Por outro lado, ela apresentava muitos limites e dificuldades na sua capacidade de responder ao que se esperava dela. 
Um aspecto comum a todos OS GD foi a crítica às condições de funcionamento e infraestrutura. Algumas escolas funcionavam sem as condições básicas de higiene e conforto. Outras não tinham laboratórios e bibliotecas adequadas. Em outros casos, embora houvesse esses equipamentos, as escolas não os usavam. Impressiona a diversidade de situações entre as escolas de uma mesma rede de ensino que, a princípio, deveriam ter as mesmas condições de funcionamento. Mais gritante ainda é o fato de que tal desigualdade se manifeste ainda nas diferenças entre os turnos, com a permanência histórica de uma política de desvalorização do ensino noturno.

Nesta escola empobrecida, do ponto de vista da sua materialidade, também as relações humanas se fazem limitadas. Os professores e gestores foram alvo de muitas queixas por parte dos alunos. Embora reconhecendo e valorizando alguns que se destacavam em relação ao coletivo de profissionais da escola, constata-se uma grande desmotivação com relação ao fazer docente. Isso contribuía para um clima escolar negativo, marcado pela desorganização e pela dificuldade dos jovens em se subjetivarem como alunos. Muitos depoimentos reconheceram a responsabilidade dos estudantes quanto a esse aspecto.

Outro aspecto comum aos GD foi a crítica dos jovens alunos a um currículo distante da sua realidade, pleiteando uma articulação maior entre os conteúdos e sua vida cotidiana. Parece-nos que a escola não vem possibilitando uma compreensão da realidade onde se inserem, uma visão sobre o mundo do trabalho e suas exigências, um conhecimento do que a universidade pode ou não oferecer, os cursos existentes com suas especificidades e demandas próprias. É muito sintomático que poucos deles tenham se referido, nos debates ocorridos, aos programas seriados de ingresso no ensino superior público no estado do Pará. Ou seja, na forma como elaboraram os seus projetos de vida, nos parece que se encontravam abandonados à própria sorte, a não ser pelo apoio da família. A escola e a sociedade em geral não lhes ofereciam muitas perspectivas. Viam-se, assim, com poucos suportes materiais e subjetivos que os possibilitassem vislumbrar possíveis caminhos nos seus futuros.

Nesse sentido, apresenta-se às escolas de ensino médio o desafio de se constituírem em uma referência, na qual os jovens possam ter acesso a reflexões, informações, habilidades e competências, dimensões importantes para a construção dos seus projetos de vida.

A pesquisa possibilitou descortinar um quadro de grandes dificuldades das escolas investigadas em dialogarem com os projetos de seus jovens. Isso se torna grave no contexto de uma sociedade que passa por grandes mudanças, com novas exigências em termos de habilidades e conhecimentos. Numa sociedade onde a incerteza e a imprevisibilidade preponderam, ao mesmo tempo herdeira e reprodutora de desigualdades históricas, qual lugar a escola ocupará na vida de seus jovens? 
Podemos nos perguntar se a postura destes jovens na elaboração dos projetos de vida não expressaria uma nova forma de desigualdade social, que se materializaria no esgotamento das possibilidades de mobilidade social para grandes parcelas da população e novas formas de dominação. Inspirados em Dubet (2006), poderíamos dizer que a sociedade joga sobre o jovem a responsabilidade de ser mestre de si mesmo. Mas, no contexto de uma sociedade desigual, além deles se verem privados da materialidade do trabalho, do acesso às condições materiais de vivenciarem a sua condição juvenil, defrontam-se com a desigualdade no acesso aos recursos para lidar com a esta nova semântica do futuro, dificultando-lhes a elaboração de projetos de vida. Como lembra este autor, o dominado é convidado a ser o mestre da sua identidade e de sua experiência social, ao mesmo tempo em que é posto em situação de não poder realizar este projeto.

\section{Notas}

1. Para uma reflexão mais aprofundada sobre a noção de juventude, ver Dayrell (2007).

2. Uma descrição detalhada da metodologia e dos resultados do conjunto da pesquisa pode ser encontrada no relatório final da pesquisa, disponível em: <www.fae.ufmg.br/objuventude>.

3. A seleção do estado em que seria realizada a pesquisa deu-se a partir da demanda do MEC, com base nos resultados do Índice de Desenvolvimento da Educação Básica (IDEB) de 2007.

4. O vídeo está disponível também em: <http://www.vimeo.com/14557744>.

5. No estado do Pará existe o Programa de Ingresso Seriado (PRISE), que é o vestibular seriado da Universidade do Estado do Pará, e o Processo Seletivo Seriado (Pss), que é o vestibular seriado da Universidade Federal do Pará.

\section{Referências}

BECK, U. La sociedad del riesgo: hacia uma nueva modernidad. Barcelona: Paidós, 1998.

DAYRELL, J. A música entra em cena: o funk e o hip hop na socialização da juventude. Belo Horizonte: ufmG, 2005.

DAYRELL, J. A escola faz juventudes? Reflexões em torno da socialização juvenil. Educação \& Sociedade, Campinas, v. 28, n. 100, p. 105-1128, out. 2007.

DUBET, F. El declive de la instituición: profesiones, sujetos e indivíduos en la modernidad. Barcelona: GEDISA, 2006.

ELIAS, N. Sobre o tempo. Rio de Janeiro: Zahar, 1989.

LECCARDI, C. Futuro breve. Le giovani donne e il futuro. Torino: Rosenberg \& Sellier, 1996. 
LECCARDI, C. Orizzonte del tempo: esperienza del tempo e mutamento sociale. Milano: Franco Angeli, 1991.

LECCARDI, C. Por um novo significado do futuro: mudança social, jovens e o tempo. Tempo Social, São Paulo, v. 17, n. 2, p. 35-57, 2005.

LEVI STRAUSS, C. Pensamento selvagem. São Paulo: Papirus, 1989.

MAUSS, M. Ensaio sobre a dádiva. Forma e razão da troca nas sociedades arcaicas. In: Mauss, M. Sociologia e Antropologia. v. II. São Paulo: Edusp, 1974. p. 37-184.

MELUCCI, A. O jogo do eu. São Leopoldo: unisinos, 2004.

PAIS, J.M. Ganchos, tachos e biscates: jovens, trabalho e futuro. Lisboa: Âmbar, 2003. SCHUTZ, A. Saggi sociologic. Torino: Utet, 1979.

Recebido em 26 de outubro de 2011.

Aprovado em 18 de novembro de 2011. 